\title{
Immunohistochemical studies of wound healing after monopolar electrocautery and ultrasound submucosal inferior nasal turbinate reduction in sheep*
}

\author{
C.S. Nousia', H. Gouveris', A. Giatromanolaki², M. Katotomichelakis', \\ P. Ypsilantis ${ }^{3}$, M. Riga' ${ }^{1}$ E. Sivridis ${ }^{2}$, J.B. Watelet ${ }^{4}$, P. Van Cauwenberge ${ }^{4}$, \\ $\checkmark$. Danielides ${ }^{1}$ \\ ' Department of Otorhinolaryngology, Faculty of Medicine, Democritus University of Thrace, Alexandroupolis, Greece \\ ${ }^{2}$ Department of Pathology, Faculty of Medicine, Democritus University of Thrace, Alexandroupolis, Greece \\ ${ }^{3}$ Laboratory of Experimental Surgery and Surgical Research, Faculty of Medicine, Democritus University of Thrace, \\ Alexandroupolis, Greece \\ ${ }^{4}$ Department of Otorhinolaryngology, Faculty of Medicine, Ghent University, Ghent, Belgium
}

Rhinology 51: 154-161, 2013 DOI:10.4193/Rhino 11.216

*Received for publication: October 11, 2011 Accepted: February 20, 2013

\section{Summary}

Background: Extracellular matrix (ECM) proteins such as fibronectin and collagen III, enzymes such as matrix metalloproteinases and macrophages have been demonstrated to intervene in nasal and paranasal sinuses wound healing.

Aim of the study: To compare concentration of ECM proteins, enzymes and the recruitment of macrophages during wound repair after monopolar electrocautery in contrast with ultrasound submucosal surgical tissue reduction of inferior nasal turbinate (INT) tested in sheep.

Materials and Methods: Prospective controlled study in sheep. Immunostaining for collagen III, fibronectin, CD68 and matrix metalloproteinase-9 (MMP9) was applied in tissue specimens of INT mucosa after monopolar electrocoagulation (MEC) and ultrasound tissue reduction (UTR). Twelve INTs were studied 1, 3 and 8 weeks post-operatively in each interventional group (MEC and UTR) and 5 INTs were studied in animals of the control group (without surgery). The immunoreactivity was quantitatively graded between $0 \%$ to $100 \%$ immunoreactivity by a blinded senior pathologist.

Results: At the end of the study period collagen III, fibronectin and MMP9 were increased in both groups compared to the levels of the control group. When compared to control group, CD68 immunoreactivity was found higher in MEC group but not in UTR group. Fibronectin subepithelial immunoreactivity exhibited a substantial negative correlation with mucosal epithelial cell necrosis, a substantial positive correlation with fibrosis in MEC-treated specimens and a significant positive correlation with sinusoid engorgement in UTR-treated specimens. Collagen III tissue immunoreactivity showed a particularly significant negative correlation with sinusoid engorgement in MEC-treated specimens.

Conclusion: Correlation of fibronectin and collagen III immunoreactivity to histopathologic findings suggests different ECM repair processes between MEC and UTR turbinate tissue reduction. The use of CD68 and MMP9 provides additional clues to the mode of actions of these techniques and to the molecular and cellular events of the nasal mucosa wound healing process.

Key words: wound healing, nasal, mucosal, turbinate, surgery, fibronectin, collagen 


\section{Introduction}

Monopolar electrocoagulation (MEC) and ultrasound tissue reduction (UTR) of the inferior turbinates are used in clinical rhinological practice as a treatment modality for inferior nasal turbinate (INT) enlargement. Nonetheless, reports describing the chronological course of the early phases of wound healing at the molecular level after surgical reduction of the inferior turbinate tissue using UTR and MEC in either humans or experimental animals are missing. Additionally, ultrasound tissue reduction is not widely used in clinical practice for INT volume reduction. The most commonly used methods are electrocautery, radiofrequency tissue volume reduction, laser surgery, conventional surgery (submucosal resection), or use of a microdebrider ${ }^{(1)}$.

In the present study, the sheep was used as an animal model to ensure adequate controlled monitoring of the chronological course of the INT wound healing process and to facilitate comparative histopathological studies. Sheep have already been used to monitor wound healing after surgical manipulation of the inferior nasal turbinate at a histopathology level ${ }^{(2,3)}$ and an immunohistochemistry level ${ }^{(4)}$. The histological similarities between the INT of sheep and human have been another important reason justifying the use of this animal model for the investigation of wound healing after INT surgery. Macroscopically, the sheep has an inferior turbinate in the shape of a step and a middle one (being much larger than the inferior one), which is typical for ruminants with a rather T-shaped form. However, the histological appearance is quite similar to that of humans. Given that the extracellular matrix plays a central role in the different phases of the wound healing process, we decided to focus on ECM-associated proteins (namely collagen III and fibronectin) and enzymes (matrix metalloproteinase 9, MMP9) more specifically during the early phases of wound healing in the nasal mucosa. These factors are mainly affecting ECM formation and maturation. Furthermore, they are also important for sustaining the epithelial repair and the background inflammatory reaction ${ }^{(5)}$. In human wound repair after sinus surgery, macrophages have been shown to play a significant role ${ }^{(6)}$, justifying the use of CD68 marker in this study.

This prospective controlled study aimed to explore the early phases of tissue repair in sheep INT mucosa after UTR and MEC at the molecular level, using tissue immunostaining for inflammatory cells (macrophages), extracellular matrix (ECM) proteins (fibronectin, collagen III), and ECM-degrading enzymes (MMP-9). Particular attention was paid to the ECM remodelling process and its correlations with the local expression of these biomarkers. These biomarkers were already shown to be of particular importance during wound healing after sinus surgery in human remodelling processes ${ }^{(6,7)}$. Nevertheless, as far as we know, there are no studies in the rhinological literature investigating systematically the presence and changes in concentration of these substances during the early wound healing phases after MEC and / or UTR.

\section{Material and Methods}

\section{Experimental design}

The experimental protocol was approved by the Animal Care and Use Committee of the local Veterinary Service since it was in compliance with Directive 86/609/EEC. Seventeen clinically healthy female sheep weighing $25-35 \mathrm{~kg}$, were used for the purpose of the study. The sheep were assigned randomly to 3 groups. Under general anaesthesia and under endoscopic visualization (using a $0^{\circ}$ degree rigid nasal endoscope), bilateral submucosal UTR of the inferior nasal turbinates (group UTR, $n=6$ animals, 12 INTs), bilateral monopolar electrocautery (MEC) of the INT (group MEC, $\mathrm{n}=6$ animals, 12 INTs) or sham operation (group Sham, $n=5$ INTs) were performed. The inferior turbinates of the UTR- and MEC-groups were further subdivided according to the time intervals. As a result, 3 subgroups ( 4 turbinates in each group) were formed within each one of groups UTR and MEC that corresponded to the postoperative conditions at weeks 1, 3 and 8 , respectively. A non-longitudinal design was used because repetitive (or multiple) surgical manipulation of the INT mucosa for biopsy purpose would expectedly have a profound impact on the mucosal histology and hence would quite possibly confound the tissue changes specifically induced by UTR and MEC.

\section{Anaesthesia - post-operative care}

After overnight fasting, the sheep were anaesthezised with xylazine $(0.2 \mathrm{mg} / \mathrm{kg}$, i.m.), atropine $(0.04 \mathrm{mg} / \mathrm{kg}$, i.m.) and ketamine (10 mg/kg, i.m.) and were endotracheally intubated. Sevoflurane $2 \%$ in oxygen was used to maintain anaesthesia. Post-operatively, animals were administered $3 \mathrm{ml}$ of long-acting intramuscular terramycin and were monitored. If decreased food intake was observed, then analgesia was administered. The postoperative period was uneventful in all animals. No animal was sacrificed.

\section{Submucosal monopolar electrocautery}

Submucosal monopolar electrocautery was performed by applying a high-frequency coagulation current via a roundpoint monopolar electrode at constant power (set at 45 Watt). The electrode was introduced at the head of the INT and was advanced towards the dorsal end of the turbinate, creating a submucosal tunnel at the medial aspect of the INT. A single coagulation was performed during the outward movement of the electrode (from the end to the head of the INT), lasting 15 seconds during each application. During cautery, every care was taken to prevent contact of the probe with the underlying bone and therefore prevent development of osteitis of the INT bony segment. 


\section{Ultrasound tissue reduction}

A Crystal Surgical Ultrasound system (Model Lora Don, Diamant Medical Equipment Ltd, Thessaloniki, Greece), consisting of a main unit and a transducer hand piece probe, was used. The main unit is a low-frequency ultrasound generator ( $44+$ $4.4 \mathrm{KHz}$ ), which is connected to an acoustical transducer and controlled by a footswitch. The electrical ultrasound frequency oscillations produced by the generator are transformed to mechanical oscillations by a positive magnetostriction transducer and transferred to a concentrator, i.e. a wave-guide operating tool. The acoustical transducer includes crystal magnetic ferrite, which, based on the principal of the piezo-electric phenomenon, transforms the low-frequency ultrasound into mechanical oscillations, which are transferred to the wave guide tools. The ultrasound system operates on a three amplitude scale, corresponding to wavelength amplitudes of 20,30 or $40 \mu \mathrm{m}$. For the present study only the $30 \mu \mathrm{m}$ - amplitude setting was used. The probe was inserted submucosally in the caudal part of the head of the inferior nasal turbinate and was kept activated during the entire period that it remained within the inferior nasal turbinate. The probe was introduced into and removed from the caudal purely submucosal (non-osseous) part of the inferior nasal turbinate with a continuous, straight longitudinal sliding motion beginning at the head, reaching the very end of the tail and finally being again extracted at the point of introduction at the head of the turbinate, in a direction parallel to the floor of the nasal cavity. The total time needed for each application ranged between 15 and $20 \mathrm{sec}$ (depending on the length of the turbinate). The time needed for the ventro-dorsal motion equalled the time needed for the reverse (dorso-ventral) motion. At the end of the procedure, it was necessary to keep the probe at the insertion site for 2-3 seconds so as to ensure haemostasis. The horizontal, rapid motion of the probe allowed immediate coagulation of the surrounding tissue at its tip.

\section{Morphological studies}

The entire inferior turbinate was excised using cold instruments (scissors) facilitated by nasal endoscopic visualization using a $0^{\circ}$ rigid nasal endoscope under general anaesthesia. Tissue samples from the inferior nasal turbinates were prepared for histological examination. Care was taken not to disrupt the delicate mucosal epithelial surface, ensuring the integrity of the samples at the time of retrieval and preparation. The bone of the samples was separated by sharp dissection. The samples were dehydrated with increasing concentrations of ethanol and embedded in paraffin blocks. Serial 3- $\mu$ m-thick tissue sections were cut in a direction vertical to the mucosal surface.

\section{Immunohistochemical Study}

Initially the $3 \mu \mathrm{m}$-cut sections were dewaxed and rehydrated in graded alcohol solutions. For heat-induced epitope retrieval, the sections were placed in citrate buffer ( $1: 10$ dilution, $\mathrm{pH}$ 7.2) and heated at $120^{\circ} \mathrm{C}$ for $3 \times 5 \mathrm{~min}$. Endogenous peroxidase activity was neutralized applying Peroxidase Block (Novocastra Laboratories Ltd, Newcastle upon Tyne, United Kingdom) for 5 min. The non-specific binding was blocked by pre-incubation with Protein Block (Novocastra Laboratories Ltd) for $5 \mathrm{~min}$ at room temperature. Slides were then incubated overnight at $4^{\circ} \mathrm{C}$ with collagen type III primary antibody (M-300, sc-28888, Santa Cruz Biotechnology, Inc., Santa Cruz, CA, USA.) diluted 1:50, matrix metalloproteinase-9 primary antibody (MMP9, clone 2C3, Menarini Industrie Farmaceutiche Riunite Srl., Florence, Italy) diluted 1:40 for 75 min, CD68 primary antibody (Menarini Industrie Farmaceutiche Riunite Srl) diluted 1:80 for 60 min and fibronectin primary antibody (Menarini Industrie Farmaceutiche Riunite Srl) diluted 1:100 for $60 \mathrm{~min}$. The slides were washed with PBS (2 $x 5 \mathrm{~min}$ ) and then incubated with Post Primary Block (Novocastra Laboratories Ltd) enhancing penetration of the subsequent polymer reagent, for 30 minutes at room temperature. Additionally, they were washed with PBS for $2 \times 5$ min and incubated with NovoLink ${ }^{\mathrm{TM}}$ polymer (Novocastra Laboratories Ltd) for 30 min at room temperature. NovoLink ${ }^{\mathrm{TM}}$ is known to recognize mouse and rabbit immunoglobulins and detect any tissuebound primary antibody. After extensive washing with PBS (2 $x 5 \mathrm{~min}$ ), the colour reaction was developed in DAB (3,3'-diaminobenzidine) for $5 \mathrm{~min}$. The sections were then counterstained with hematoxylin/eosin, dehydrated and mounted.

All aforementioned antibodies were antibodies against human tissue antigens. For every antibody, we used positive control of human tissues. As a result we could assess the positive or negative staining results.

Immunohistological grading of the CD68 staining was performed quantitatively by a blinded senior pathologist determining the percentage of the positive cells among the inflammatory cells throughout the section. Similarly, the evaluation of fibronectin-, collagen III- and MMP-9-immunoreactivity was determined by the relative percentage of immunopositivity inside the subepithelial compartment. Previously, the pathologist had examined three slices to establish the staining range and calibrate the respective 100-point scale response.

\section{Controls}

Normal rabbit immunoglobulin-G substituted the primary antibody as negative control. Furthermore, staining with omission of the primary antibody was also performed as negative control.

\section{Histopathology}

Using hematoxylin/eosin-stained sections, stromal fibrosis, submucosal interstitial space volume (ISV), mucosal epithelial cell necrosis and / or shedding, submucosal inflammation and sinusoid engorgement were assessed using a semi-quantitative four-point histopathological grading scale $(0=$ absence, $1=$ 
mild, $2=$ medium, 3 = pronounced ${ }^{(6)}$. Histopathology results have been extensively described previously $(2,3)$.

\section{Statistical analysis}

Statistical analysis was performed using the Statistical Package for the Social Sciences (SPSS), version 13.0 (SPSS, Inc., Chicago, IL, USA). All continuous variables were expressed as median and range; the mean \pm standard deviation (SD) of these variables was also given. As the distribution of these variables did not appear to be normal, a Shapiro-Wilk test for normality was performed and data were analysed using the Mann-Whitney U-test and the Kruskal-Wallis oneway ANOVA, to assess differences of these characteristics between two or more groups of animals. Post hoc analysis was performed using Mann-Whitney U-test; due to the small sample sizes, Bonferroni's adjustment was not performed. All tests were two-tailed and statistical significance was considered for $p$ values $<0.05$. Spearman's rho correlation coefficients were calculated between histopathological and immunostaining staging.

\section{Results}

Expression of CD68, MMP-9, fibronectin and collagen III during the postoperative period

At week 1, collagen III and CD68 immunoreactivities were significantly higher in both treatment groups when compared to the control group. The grading of fibronectin immunopositivity was similar to the control group in both interventional groups at that time whereas only UTR-treated samples exhibited a stronger MMP-9 immunostaining than the controls.

At week 3, collagen III, fibronectin and CD68 immunoreactivities were significantly higher in both treatment groups compared to controls. At week 3, only UTR-treated samples exhibited again a stronger MMP-9 immunostaining than controls, whereas non-significant differences were observed between MEC-treated samples and controls.

At the end of the study period (week 8 postoperatively) collagen III, fibronectin and MMP9 tissue immunoreactivity increased in both groups compared to controls. CD68 immunoreactivity was higher in MEC group than in controls while it showed no difference between controls and UTR group.

No difference was observed between the two intervention groups in terms of immunopositivity or localisation of collagen III, fibronectin, MMP9 and CD68 at any of the tested postoperative weeks (1, 3 and 8$)$.

Results are displayed in Tables 1, 2, 3 and 4 and examples are depicted in Figures 1 and 2.

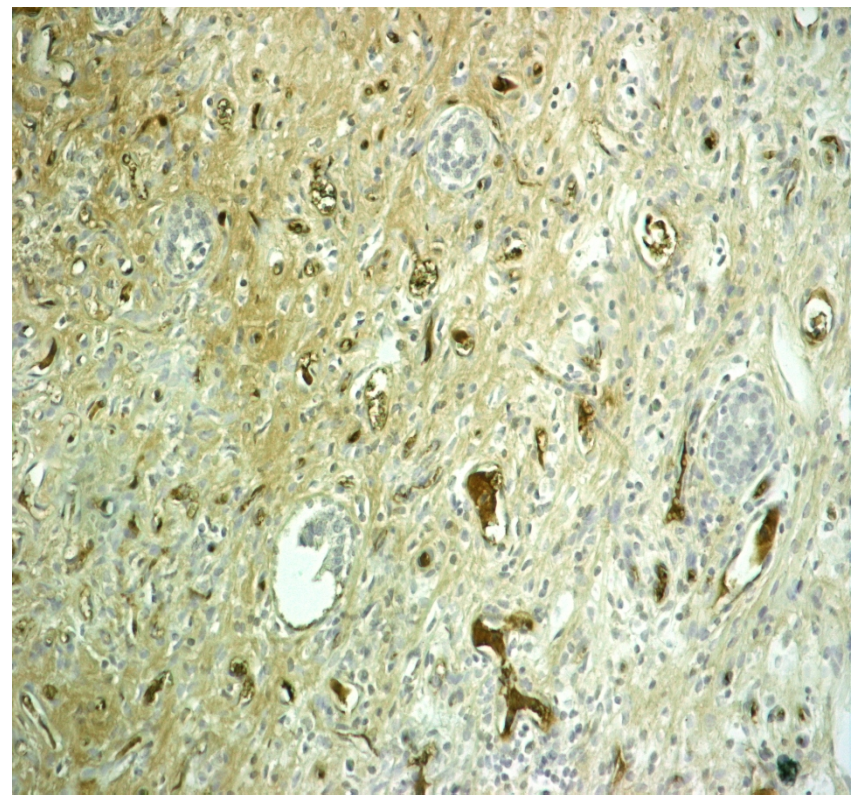

Figure 1. Collagen III immunoreactivity at a 3rd postoperative week specimen after MEC-treatment (200-fold magnification).

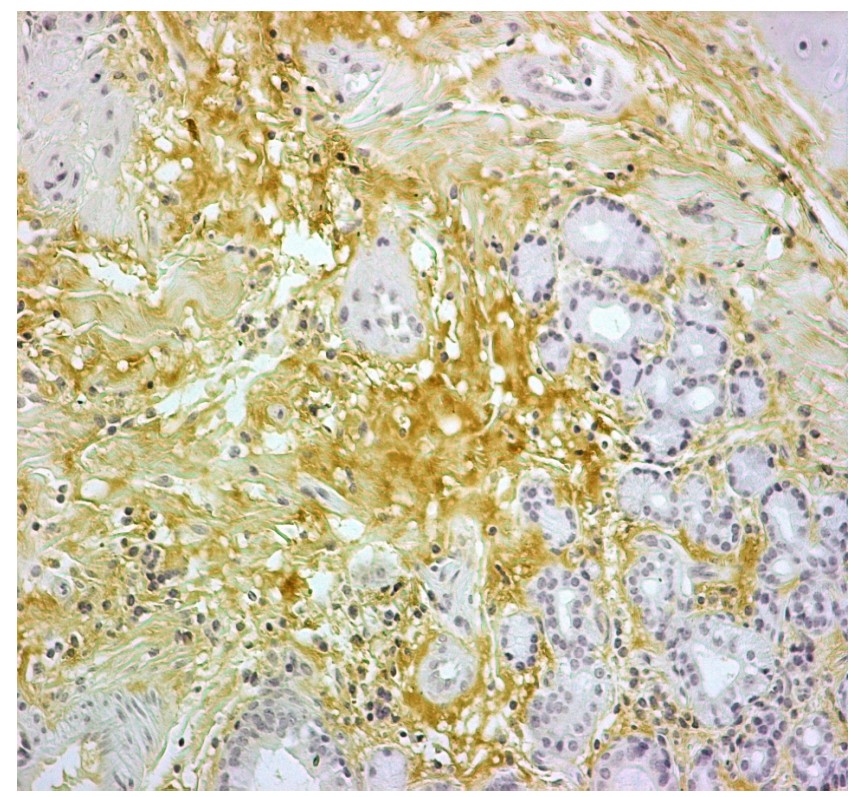

Figure 2. Fibronectin immunoreactivity at a 3rd postoperative week specimen after UTR-treatment (200-fold magnification).

\section{Correlation with histopathological changes}

The results of the correlation between the histopathological and immune staining grading showed that fibronectin immunoreactivity exhibited a substantial $(r=-0.733, p=0.007)$ negative correlation with mucosal epithelial cell necrosis, a substantial positive correlation ( $r=0.674, p=0.016$ ) with fibrosis in MEC-treated specimens and a significant $(r=0.837, p=0.001)$ positive correlation with sinusoid engorgement in UTR-treated speci- 


\begin{tabular}{|c|c|c|c|c|}
\hline & MEC & UTR & Control group & $\begin{array}{c}\text { MEC } \\
\text { VS. } \\
\text { UTR }\end{array}$ \\
\hline $\begin{array}{l}\text { 1st week } \\
\text { Median (range) } \\
\text { Mean } \pm \text { SD }\end{array}$ & $\begin{array}{c}45(20-70) \\
45(23.8)\end{array}$ & $\begin{array}{l}35(20-80) \\
42.5(26.3)\end{array}$ & $\begin{array}{c}5(0-20) \\
5.5(6.43)\end{array}$ & 1.000 \\
\hline $\begin{array}{l}\text { 3rd week } \\
\text { Median (range) } \\
\text { Mean } \pm \text { SD }\end{array}$ & $\begin{array}{c}40(5-90) \\
43.75(35.9)\end{array}$ & $\begin{array}{c}35(10-60) \\
35(20.82)\end{array}$ & & 0.885 \\
\hline $\begin{array}{l}\text { 8th week } \\
\text { Median (range) } \\
\text { Mean } \pm \text { SD }\end{array}$ & $\begin{array}{c}30(10-50) \\
30(16.33)\end{array}$ & $\begin{array}{c}50(30-50) \\
45(10.0)\end{array}$ & & 0.155 \\
\hline $1^{\text {st }}$ vs 3rd week & 0.885 & 0.770 & & \\
\hline $1^{\text {st }}$ vs 8 th week & 0.375 & 0.457 & & \\
\hline $3^{\text {rd }}$ vs 8th week & 0.655 & 0.457 & & \\
\hline $1^{\text {st }}$ week vs control & 0.005 & 0.005 & & \\
\hline $3^{\text {rd }}$ week vs control & 0.025 & 0.009 & & \\
\hline $8^{\text {th }}$ week vs control & 0.009 & 0.004 & & \\
\hline
\end{tabular}

Table 1. Overview of the grades of the immunohistochemical changes in collagen III over time after application of submucosal MEC and UTR. Immunohistochemical grading of the changes in collagen III immunoreactivity was performed quantitatively using a 100 -point scale $(0 \%=a b s e n c e$, $100 \%=$ pronounced). The respective $p$-values resulting from comparisons of the respective morphological changes between weeks within the same treatment group, between each treatment group and the control group, as well as between the two treatment groups are also depicted (SD = standard deviation).

\begin{tabular}{|c|c|c|c|c|}
\hline & MEC & UTR & Control group & $\begin{array}{l}\text { MEC } \\
\text { vs. } \\
\text { UTR }\end{array}$ \\
\hline $\begin{array}{l}\text { 1st week } \\
\text { Median (range) } \\
\text { Mean } \pm \text { SD }\end{array}$ & $\begin{array}{c}10(0-20) \\
10(8.16))\end{array}$ & $\begin{array}{l}25(0-60) \\
27.5(25.0)\end{array}$ & $\begin{array}{c}5(0-40) \\
8.5(12.7)\end{array}$ & 0.240 \\
\hline $\begin{array}{l}\text { 3rd week } \\
\text { Median (range) } \\
\text { Mean } \pm \text { SD }\end{array}$ & $\begin{array}{l}35(20-60) \\
37.5(20.62)\end{array}$ & $\begin{array}{c}35(20-40) \\
32.5(9.57)\end{array}$ & & 0.766 \\
\hline $\begin{array}{l}\text { 8th week } \\
\text { Median (range) } \\
\text { Mean } \pm \text { SD }\end{array}$ & $\begin{array}{c}25(10-70) \\
32.5(26.3)\end{array}$ & $\begin{array}{c}30(20-80) \\
40(27.08)\end{array}$ & & 0.457 \\
\hline $1^{\text {st }} v s$ rd week & 0.037 & 0.557 & & \\
\hline $1^{\text {st }}$ vs 8 th week & 0.102 & 0.457 & & \\
\hline $3^{\text {rd }}$ vs 8th week & 0.767 & 0.881 & & \\
\hline $1^{\text {st }}$ week vs control & 0.421 & 0.167 & & \\
\hline $3^{\text {rd }}$ week vs control & 0.014 & 0.017 & & \\
\hline $8^{\text {th }}$ week vs control & 0.031 & 0.018 & & \\
\hline
\end{tabular}

Table 2. Overview of the grades of the immunohistochemical changes in fibronectin over time after application of submucosal MEC and UTR. Immunohistochemical grading of the changes in fibronectin immunoreactivity was performed quantitatively using a 100 -point scale $(0 \%=a b s e n c e$, $100 \%=$ pronounced). The respective $p$-values resulting from comparisons of the respective morphological changes between weeks within the same treatment group, between each treatment group and the control group, as well as between the two treatment groups are also depicted. 


\begin{tabular}{|c|c|c|c|c|}
\hline & MEC & UTR & Control group & $\begin{array}{c}\text { MEC } \\
\text { vs. } \\
\text { UTR }\end{array}$ \\
\hline $\begin{array}{l}\text { 1st week } \\
\text { Median (range) } \\
\text { Mean } \pm \text { SD }\end{array}$ & $\begin{array}{c}1(1-3)) \\
1,50(1,0)\end{array}$ & $\begin{array}{l}2,5(0-10) \\
3,75(4,35)\end{array}$ & $\begin{array}{l}0 \\
0\end{array}$ & 0,457 \\
\hline $\begin{array}{l}\text { 3rd week } \\
\text { Median (range) } \\
\text { Mean } \pm \text { SD }\end{array}$ & $\begin{array}{l}0,50(0-2) \\
0,75(0,96)\end{array}$ & $\begin{array}{c}1,5(0-5) \\
2,00(2,16)\end{array}$ & & 0,369 \\
\hline $\begin{array}{l}\text { 8th week } \\
\text { Median (range) } \\
\text { Mean } \pm \text { SD }\end{array}$ & $\begin{array}{l}0,50(0-2) \\
0,75(0,96)\end{array}$ & $\begin{array}{l}0 \\
0\end{array}$ & & 0,131 \\
\hline $1^{\text {st }}$ vs 3rd week & 0,278 & 0,559 & & \\
\hline $1^{\text {st }}$ vs 8 th week & 0,278 & 0,047 & & \\
\hline $3^{\text {rd }}$ vs 8th week & 1,000 & 0,047 & & \\
\hline $1^{\text {st }}$ week vs control & $<0,001$ & 0,003 & & \\
\hline $3^{\text {rd }}$ week vs control & 0,020 & 0,003 & & \\
\hline $8^{\text {th }}$ week vs control & 0,020 & 1,000 & & \\
\hline
\end{tabular}

Table 3. Overview of the grades of the immunohistochemical changes in CD68 over time after application of submucosal MEC and UTR. Immunohistochemical grading of the changes in CD68 immunoreactivity was performed quantitatively using a 100 -point scale $(0 \%=a b s e n c e, 100 \%=$ pronounced). The respective $p$-values resulting from comparisons of the respective morphological changes between weeks within the same treatment group, between each treatment group and the control group, as well as between the two treatment groups are also depicted.

\begin{tabular}{|c|c|c|c|c|}
\hline & MEC & UTR & Control group & $\begin{array}{l}\text { MEC } \\
\text { vs. } \\
\text { UTR }\end{array}$ \\
\hline $\begin{array}{l}\text { 1st week } \\
\text { Median (range) } \\
\text { Mean } \pm \text { SD }\end{array}$ & $\begin{array}{c}40(0-5) \\
1,25(2,50)\end{array}$ & $\begin{array}{l}2,5(0-10) \\
3,75(4,79)\end{array}$ & $\begin{array}{l}0 \\
0\end{array}$ & 0,405 \\
\hline $\begin{array}{l}\text { 3rd week } \\
\text { Median (range) } \\
\text { Mean } \pm \text { SD }\end{array}$ & $\begin{array}{c}0(0-5) \\
1,25(2,50)\end{array}$ & $\begin{array}{c}5(0-10) \\
5,00(4,08)\end{array}$ & & 0,155 \\
\hline $\begin{array}{l}\text { 8th week } \\
\text { Median (range) } \\
\text { Mean } \pm \text { SD }\end{array}$ & $\begin{array}{c}3(0-10) \\
4,00(4,55)\end{array}$ & $\begin{array}{c}2(0-2) \\
1,5(1,00)\end{array}$ & & 0,655 \\
\hline $1^{\text {st }}$ vs 3rd week & 1,000 & 0,647 & & \\
\hline $1^{\text {st }}$ vs 8 th week & 0,215 & 0,762 & & \\
\hline $3^{\text {rd }}$ vs 8th week & 0,215 & 0,178 & & \\
\hline $1^{\text {st }}$ week vs control & 0,114 & 0,020 & & \\
\hline $3^{\text {rd }}$ week vs control & 0,114 & 0,003 & & \\
\hline $8^{\text {th }}$ week vs control & 0,003 & 0,003 & & \\
\hline
\end{tabular}

Table 4. Overview of the grades of the immunohistochemical changes in MMP9 over time after application of submucosal MEC and UTR. Immunohistochemical grading of the changes in MMP 9 immunoreactivity was performed quantitatively using a 100 -point scale $(0 \%=$ absence, $100 \%=$ pronounced). The respective $p$-values resulting from comparisons of the respective morphological changes between weeks within the same treatment group, between each treatment group and the control group, as well as between the two treatment groups are also depicted. 
mens. Collagen III tissue immunoreactivity showed a remarkable $(r=-0.876, p<0.001)$ negative correlation with sinusoid engorgement in MEC-treated specimens. However, MMP9 and CD68 did not show any significant correlation with histopathological findings in MEC- and UTR-treated specimens.

\section{Discussion}

In previously published manuscripts, the histopathology findings at the microsopic level after UTR-treatment of the inferior nasal turbinates in sheep compared to controls have been presented ${ }^{(2)}$. Additionally, the comparison between the histopathological findings (again at the microscopic level) between MEC and radiofrequency tissue ablation (RTA) of the inferior nasal turbinate in another series of experiments in sheep have been reported ${ }^{(3)}$. More recently, findings at the molecular level in inferior nasal turbinates involving immunochemistry staining for collagen III, fibronectin, CD68 and matrix metalloproteinase-9 (MMP9) after application of RTA in sheep turbinates have been presented ${ }^{(4)}$. In the present report, we present a comparison of the immunohistochemistry findings regarding staining patterns of collagen III, fibronectin, CD68 and matrix metalloproteinase-9 (MMP9) between turbinates treated by MEC, turbinates treated by UTR and controls in sheep.

As expected from the literature, fibronectin and collagen III follow parallel changes in their respective expression patterns in both interventional groups (i.e. MEC- and UTR- treated turbinates), compared to the control group, suggesting their major involvement in wound healing, especially in fibrosis formation. As oestrogens have an effect of nasal swelling and the menstrual cycle may influence wound healing parameters there was concern that this fact may confound wound healing studies' findings in female sheep. Nonetheless, other studies of wound healing in the nasal and paranasal cavities have also used the female sheep as an animal model and there is previous experience in using female sheep for studying inferior nasal turbinate wound healing successfully ${ }^{(8)}$. In view of the aforementioned potentially confounding oestrogen effect, monitoring of the hormonal state in female sheep in future studies is recommended.

In UTR-treated specimens, the normal loose connective tissue was replaced by extensive fibrosis with scattered subepithelial islands of inflammatory cells, and a marked decrease in large venous sinusoids was observed throughout the submucosal stroma. Although partial and/or complete epithelial denudation was found in large regions of the mucosa alongside normal-appearing, pseudo-stratified, ciliated columnar respiratory epithelium in 1-week samples, this epithelial denudation was almost absent at week 8 . A well-defined basement membrane was present across the treated areas in all UTR-specimens ${ }^{(2)}$. In MEC-treated INTs the partial and/or complete epithelial denudation was found in larger regions of the mucosa than in UTR- treated specimens. Additionally, there were MEC-treated INT specimens in which the continuity of the basement membrane was focally disrupted ${ }^{(3)}$.

Nonetheless, as derived from the correlating statistical analysis, the present differences during the progression of fibrosis are shown by their strong interdependence with other histomorphologic factors related to fibrosis, such as mucosal epithelial cell necrosis and sinusoid engorgement.

Fibronectin (FN) is a major component of the extracellular matrix and can exist in two main forms: plasma and cellular FN. Cellular FN is able to induce fibroblast differentiation ${ }^{(9)}$. FN requires the help of cells to assemble into a functional fibrillar matrix, which then orchestrates the assembly of other ECM proteins and promotes adhesion, migration and signalling of many types of cells. Fibrillogenesis and cell migration is initiated and governed by cell surface integrins that bind to specific sites in the FN molecule ${ }^{(10)}$.

Besides its role in the maintenance of the epithelial and ECM integrity, FN also plays an important role in regulating the vascular remodeling response ${ }^{(11)}$. As demonstrated in the present study, FN could assume a major recruiting and remodelling role at both the ECM and vascular level during INT wound healing. The organization and maintenance of type I and III collagen fibril network in the ECM depends on the presence of an organized, fibrillar FN matrix ${ }^{(12)}$. Some authors postulated that deposition of collagen III into matrix fibrils is FN-dependent but can also occur through interactions with an ECM component other than FN (12). The requirement of matrix FN for collagen I and III deposition and maintenance suggest that FN fibrils form a template for collagen I and III deposition ${ }^{(12)}$. Type III collagen (ColIII), expressed in early granulation tissue, has been suggested to play a prominent role in cutaneous wound repair. Type III collagen deficiency (ColllI+/-) in aged mice resulted in accelerated wound closure with increased wound contraction and Collll-deficient mice had increased myofibroblast density in the wound granulation tissue (13).

The CD68 antigen was used as an established marker of tissue macrophages in nasal musosa wound healing studies ${ }^{(6)}$. Macrophages, which arrive at the wound later than any other inflammatory cells, operate as voracious phagocytes, clearing the wound of all matrix and cell debris including fibrin and spent neutrophils ${ }^{(14)}$. The fact that macrophages $\left(\mathrm{CD} 68^{+}\right)$are present at baseline levels at week 8 postoperatively in UTR-treated INTs suggests that the wound healing process is very advanced and rather completed at this stage. On the contrary, macrophages are still present at week 8 in MEC-treated specimens, suggesting that there is still an ongoing, more prolonged, wound healing process compared to UTR-treated INTs.

The amounts of MMP-9 in nasal fluid and in ECM can significantly and independently predict the healing quality after sinus surgery in human ${ }^{(7)}$. Neutrophils were suggested to be the 
major source of increased MMP-9 expression, which was linked to poor healing quality in humans. Nonetheless, it should be stressed that macrophages can also be a significant source of MMP-9. In the present study (Table 4), MMP-9 concentration reaches its peak at week 8 in MEC-treated INTs, suggesting again (as is the case with CD68 / macrophages) a delayed functional role for neutrophils after this treatment modality and a resulting delayed wound healing process, compared to UTR-treatment (in which MMP-9 concentration peeks at postoperative week 3). However, knowing that macrophages can also be a source of MMP-9 in asthma or in bone healing ${ }^{(15,16)}$, these results should be extended by specific analyses on the local MMP-9 release and activation processes as well as recruitment and activation of macrophages and neutrophils.

This study also confirms the suitability of the sheep model for exploring INT mucosal wound healing and the high integration of remodeling processes involved during the repair process after INT surgery. The issue of the high amount of tissue samples usually needed for histomorphological and immunohistochemical studies can be adequately addressed in this model. However, as in all animal models, the translation of sheep findings to human conditions should be done with caution.

\section{Acknowledgments}

The authors would like to acknowledge the expert assistance of Prof. Gregorios Trypsianis (University of Thrace School of Medicine, Alexandroupolis, Greece) in the statistical processing of the generated data.

No sponsor provided any funding for the research presented in this manuscript.

\section{Authorship contribution}

JBW, PVC, VD: study design; CSN, AG, PY, VD: execution of the experiments; CSN, HG, AG, MK, MR, ES, JBW, PVC, VD: data analysis and interpretation; CSN, MK, MR: manuscript preparation; HG, PY, JBW: manuscript preparation and review; AG, ES, PVC, VD review of the manuscript.

\section{Conflict of interest}

The authors have no conflict of interest to declare.

\section{References}

1. Chang CWD, Ries WR. Surgical treatment of the inferior turbinate: new techniques Curr Opin Otolaryngol Head Neck Surg. 2004; 12: 53-57.

2. Nousia C, Gouveris H, Giatromanolaki A Ypsilantis P, Katotomichelakis M, Watelet JB, Simopoulos K, Danielides V. Ultrasound submucosal inferior nasal turbinate reduction technique: histological study of wound healing in a sheep model. Rhinology. 2010; 48: 169-173.

3. Gouveris H, Nousia C, Giatromanolaki A, Riga M, Katotomichelakis M, Ypsilantis $P$, Sivridis E, Danielides V. Inferior nasal turbinate wound healing after submucosal radiofrequency tissue ablation and monopolar electrocautery: histologic study in a sheep model. Laryngoscope. 2010; 120: 1453-9.

4. Gouveris H, Nousia C, Giatromanolaki A, Riga $M$, Katotomichelakis $M$, Papathanasiou J, Watelet JB, Danielides V. Immunohistological study of wound healing after submucosal radiofrequency tissue ablation of inferior nasal turbinate in a sheep model. Am J Rhinol Allergy. 2011; 25: 131-136.

5. Watelet JB, Bachert C, Gevaert P, Van Cauwenberge P. Wound healing of the nasal and paranasal mucosa: a review. Am J Rhinol. 2002;16: 77-84.

6. Watelet JB, Demetter P, Claeys C, Cauwenberge $\mathrm{P}$, Cuvelier C, Bachert C. Wound healing after paranasal sinus surgery: neutrophilic inflammation influences the outcome. Histopathology. 2006; 48 174-181.
7. Watelet JB, Demetter P, Claeys C, Van Cauwenberge P, Cuvelier C, Bachert C. Neutrophil-derived metalloproteinase-9 predicts healing quality after sinus surgery. Laryngoscope. 2005; 115: 56-61.

8. Kakarala K, Faquin WC, Cunningham MJ Radiofrequency volumetric tissue reduction of the inferior turbinate in a sheep model. Laryngoscope. 2012; 122: 724-729.

9. Kohan M, Muro AF, White ES, Berkman N EDA-containing cellular fibronectin induces fibroblast differentiation through binding to $\{$ alpha\} 4 \{beta\}7 integrin receptor and MAPK/Erk 1/2-dependent signaling. FASEB J .2010; 24: 4503-4512.

10. Leiss M, Beckmann K, Girós A, Costell M, Fässler R. The role of integrin binding sites in fibronectin matrix assembly in vivo. Curr Opin Cell Biol. 2008; 20: 502-507.

11. Chiang HY, Korshunov VA, Serour A, Shi F, Sottile J. Fibronectin is an important regulator of flow-induced vascular remodeling. Arterioscler Thromb Vasc Biol. 2009; 29: 1074-1079.

12. Sottile J, Shi F, Rublyevska I, Chiang HY, Lust J, Chandler J. Fibronectin-dependent collagen I deposition modulates the cell response to fibronectin. Am J Physiol Cell Physiol. 2007; 293: C1934-1946.

13. Volk SW, Wang Y, Mauldin EA, Liechty KW, Adams SL. Diminished Type III Collagen Promotes Myofibroblast Differentiation and Increases Scar Deposition in Cutaneous Wound Healing. Cells Tissues Organs. 2011; 194: 25-37

14. Martin P, Leibovich SJ. Inflammatory cells during wound repair: the good, the bad and the ugly. Trends Cell Biol. 2005; 15: 599607

15. Ohbayashi H, Shimokata K. Matrix metalloproteinase-9 and airway remodeling in asthma. Curr Drug Targets Inflamm Allergy. 2005; 4: 177-181.

16. Zambuzzi WF, Paiva KB, Menezes R, Oliveira RC, Taga R, Granjeiro JM. MMP-9 and CD68(+) cells are required for tissue remodeling in response to natural hydroxyapatite. J Mol Histol 2009; 40: 301-309.

Prof. Vasilios Danielides

Dept. of Otorhinolaryngology - Head and Neck Surgery

Alexandroupolis University Hospital Dragana

68100 Alexandroupolis

Greece

Tel: +30-255-107 4544

Fax: +30-255-103 0441

E-mail:vdanielidis@hotmail.com 